\title{
Achieving high-value cardiac imaging: challenges and opportunities.
}

\author{
David H Wiener \\ Division of Cardiology, Jefferson Heart Institute
}

Follow this and additional works at: https://jdc.jefferson.edu/cardiologyfp

Part of the Cardiology Commons

Let us know how access to this document benefits you

\section{Recommended Citation}

Wiener, David H, "Achieving high-value cardiac imaging: challenges and opportunities." (2014).

Division of Cardiology Faculty Papers. Paper 44.

https://jdc.jefferson.edu/cardiologyfp/44

This Article is brought to you for free and open access by the Jefferson Digital Commons. The Jefferson Digital Commons is a service of Thomas Jefferson University's Center for Teaching and Learning (CTL). The Commons is a showcase for Jefferson books and journals, peer-reviewed scholarly publications, unique historical collections from the University archives, and teaching tools. The Jefferson Digital Commons allows researchers and interested readers anywhere in the world to learn about and keep up to date with Jefferson scholarship. This article has been accepted for inclusion in Division of Cardiology Faculty Papers by an authorized administrator of the Jefferson Digital Commons. For more information, please contact: JeffersonDigitalCommons@jefferson.edu. 
Achieving High Value Cardiac Imaging - Challenges and Opportunities

David H. Wiener, M.D., F.A.S.E.

$\begin{array}{ll}\text { Institution: } & \begin{array}{l}\text { Thomas Jefferson University } \\ \text { Philadelphia, PA }\end{array} \\ \text { Corresponding: } & \begin{array}{l}\text { David H. Wiener, M.D., F.A.S.E. } \\ \text { Jefferson Heart Institute } \\ \end{array} \\ & 925 \text { Chestnut Street } \\ & \text { Philadelphia, PA 19017 } \\ & \text { Work Phone: 215-955-9851 } \\ & \text { Work Fax: 215-503-3976 } \\ & \text { Cell Phone: 267-307-4361 } \\ & \text { E-mail: david.wiener@jefferson.edu }\end{array}$

Reprint Requests: David H. Wiener, M.D. (david.wiener@jefferson.edu) 


\begin{abstract}
Cardiac imaging is under intense scrutiny as a contributor to health care costs, with multiple initiatives under way to reduce and eliminate inappropriate testing. Appropriate use criteria are valuable guides to selecting imaging studies, but until recently have focused on the test rather than the patient. Patientcentered means are needed in order to define the true value of imaging for patients in specific clinical situations. This article provides a definition of high value cardiac imaging. A paradigm to judge the efficacy of echocardiography in the absence of randomized controlled trials is presented. Candidate clinical scenarios are proposed in which echocardiography constitutes high value imaging, as well as stratagems to increase the likelihood that high value cardiac imaging takes place in those circumstances.
\end{abstract}


Cardiac imaging has come under intense scrutiny as a contributor to rising health care costs in the United States. Attention has been focused on the number of cardiac imaging studies performed, including echocardiography. Volume is easy to measure; a far more difficult - and more important - task is to ascertain the value of imaging for specific patients or groups of patients. The critical issue is not how many studies are being done, but that they are done in circumstances where the results will enhance the care of the patient - and not done when the results will not make a difference - so that studies lead to better outcomes.

Increased demand for testing is due to both patient- and physician-related factors (1, 2). Among the drivers are physician training which encourages a culture of completeness regardless of cost or of effect on others; misaligned financial incentives; effective marketing of new technologies to physicians in the absence of comparative effectiveness data with which physicians can assess the value of that technology; and fear of malpractice suits, encouraging the practice of defensive medicine. On the patient side, Americans are enamored of high technology and may perceive that more tests are by definition equal to better care. Direct-to-consumer marketing influences patients' preferences for testing; and a health care system in which patients are insulated from the true fiscal costs of testing also drives demand.

Recent data indicate that the rate at which cardiac imaging is performed not only is no longer increasing but has begun to drop. While the General Accounting Office (GAO) reported in 2008 that Medicare spending on imaging services under the Part B physician fee schedule more than doubled from 2000 through 2006, a subsequent MEDPAC Report to Congress noted that annual rate of growth in the number of echocardiograms provided per Medicare beneficiary was only 2.6\% between 2005 and 2009, 
and decreased by $0.8 \%$ per annum between 2009 and 2010. (3) On the cost side, payments to cardiologists for noninvasive diagnostic imaging decreased a total of 33\% between 2006 and 2010, reversing the increases seen during the preceding six years. (4) Multiple explanations have been cited for this phenomenon, which is sometimes referred to as "bending the cost curve." They include the promulgation of appropriate use criteria for cardiac imaging by professional societies such as the American College of Cardiology Foundation (ACCF) and the American Society of Echocardiography (ASE), among others. These documents evaluate the relative benefits and risks of an imaging study to determine whether it is reasonable to consider performing the study for a specific indication. (5) The terminology used to describe the three appropriateness categories has evolved for greater clarity since their original publication. Studies for a specific indication were initially divided into Appropriate, Uncertain or Inappropriate categories. The terminology has been revised to Appropriate Care, May be Appropriate Care, and Rarely Appropriate Care, recognizing that a study which is rarely appropriate may be precisely correct for a specific patient. (6) Stated another way, the goal for Rarely Appropriate studies is not zero! Education programs such as the American Board of Internal Medicine's "Choosing Wisely" campaign have been directed at patient and providers. Commercial insurers have turned to radiology benefits managers (RBM's) in an attempt to reduce test ordering which they deem inappropriate, while Medicare has adopted payment reductions to providers.

\section{Reducing Overutilization}

The interest in limiting inappropriate cardiac testing stems not just from containing costs. Excess testing carries the potential for downstream ill effects. When a study which may have good specificity is ordered on a population in whom a disorder has a low prevalence, the few "abnormal" results are more likely to be false positives than true positives. This can cause anxiety on the part of the patient and leads to unwarranted further testing which carries its own inherent risks. Conversely, a false negative result 
provides false reassurance and the potential for delayed diagnosis. These concepts are explicitly recognized by the ACCF in its definition of an appropriate imaging study as "one in which the expected incremental information, combined with clinical judgment, exceeds the expected negative consequences by a sufficiently wide margin for a specific indication that the procedure is generally considered acceptable care and a reasonable approach for the indication." (5)

Appropriate use stratagems have been employed to examine and vet imaging studies once they have been ordered, to determine whether they are being ordered for appropriate reasons. Methodologies focusing on studies after they have been ordered are suited to reducing overutilization. Research in community as well as academic settings has shown that from $9-20 \%$ of transthoracic and stress echocardiograms are ordered for inappropriate indications. (7-11) A much smaller proportion of requested transesophageal studies is rated as inappropriate. (12) The reasons for the disparity have not been studied, but might include differences in specialties of the ordering physicians (i.e., cardiologists versus non-cardiologists) for transesophageal studies compared with transthoracic or stress echocardiography. The ease with which a transthoracic or stress echocardiogram can be ordered, contrasted with the fact that transesophageal studies are semi-invasive and are directly performed by a cardiologist who must actively assent to their performance, may play a role in differing rates of appropriateness. Applying appropriate use criteria had previously been a manual undertaking, consisting of matching the clinical scenario to a list of criteria on paper and uncovering the appropriateness score. An application for myocardial perfusion imaging is available for both major smartphone platforms, and one for echocardiography has been announced. The American College of Cardiology has designed Imaging in FOCUS, a voluntary, web-based decision support program designed to reduce inappropriateness in cardiac imaging. FOCUS demonstrated a reduction in inappropriate SPECT myocardial perfusion imaging ordering among participants, from $11 \%$ of studies before using FOCUS to 5\% after. (13) ASE has co-developed a FOCUS module for transthoracic echocardiography. It is 
reasonable to expect comparable improvements in the degree of study appropriateness when this tool is applied to transthoracic echocardiography, but this hypothesis has yet to be tested beyond a pilot study. (11). FOCUS is evolving into a robust, multi-modality program which links with commercially available electronic health records and provides integrated decision support at the point of order entry.

\section{Defining and identifying high value imaging}

In the quest for high value imaging, rooting out cardiac imaging studies which are of questionable appropriateness by looking at the study is one part of the solution. However, if examining appropriateness begins once a test has been ordered, the process is entered at the midpoint of the dimensions of care framework for evaluating the quality of cardiac imaging described by the ACCF (Figure 1). This framework starts with the patient, recognizing that efforts at enhancing the value of imaging studies must be patient-centric rather than test-centric. Focusing efforts at the patient level

uncovers not only which patients do not need an imaging study, but also identifies patients who should have imaging studies to detect or risk stratify diseases. Such high value imaging may lead to management changes which improve outcomes; or alternatively, lead to the imaging study which most conclusively and efficiently excludes a disease, thereby reducing both patient anxiety and downstream costs. This approach might better be conceptualized as "bending the value curve," since the goal of managing cardiac imaging is not just lower costs, but higher value to the patient and the health system. The concept of developing an outcomes-based imaging cycle backed by evidence is not new (15) but bears explication, particularly as the American health care system continues to transform.

Value in health care has been defined as health outcomes achieved per dollar spent. (16) Determining what is high value cardiac imaging requires measurable outcomes which are specific to a given condition. Outcomes, in the numerator, must be achieved efficiently; that is, the total cost of care for 
the condition must be calculated, and not merely the cost of an individual service. A more expensive test which reduces the overall cost of care may be a good investment of health care dollars. Diagnostic studies do not by themselves cure, or change outcomes. Yet, high value imaging, by being performed in the correct part of the care cycle, conceptually can reduce the overall cost of care if it leads to a better health outcome. While the most critical outcomes for patients are increased survival, and recovery or improved health, other metrics include time to recovery, avoiding treatment-related side effects, avoidance of complications, sustained health and function, and avoiding care-induced illnesses.

The highest level of evidence for the value of an imaging study would come from a randomized, controlled trial which measures specified outcomes. An example of such a study is the PROspective Multicenter Imaging Study for Evaluation of Chest Pain (PROMISE) Trial, a randomized trial funded by the National Heart, Lung and Blood Institute of the clinical effectiveness of diagnostic strategies in patients with chest pain, who are randomized to either functional (exercise ECG, stress echocardiography or stress nuclear) testing versus anatomic testing (coronary CT angiography). (17) Randomized trials for an accepted technology which is already in clinical use - such as echocardiography - as part of a diagnostic and treatment strategy are unlikely to be conducted, due to the large number of conditions for which echocardiography is performed, and perhaps also due to lack of sponsor enthusiasm for investing in what are perceived to be mature technologies.

An alternate, frequently cited paradigm to judge the value of imaging employs a six-tiered, hierarchical model to conceptualize diagnostic imaging as part of a larger system whose goal is to treat patients effectively and efficiently. Level 1 is technical efficacy, comprising variables needed to produce a high quality image. Level 2 is diagnostic accuracy efficacy, such as percent of correct diagnoses, positive and negative predictive value, sensitivity and specificity, as well as receiver operating curves. Level 3 , diagnostic thinking efficacy, describes the percentage of cases in which the image was helpful in making 
the diagnosis, the difference in the clinician's estimation of post- versus pre-test probability and the like. Level 4, therapeutic efficacy, consists of the percentage of times the image affects management or changes the diagnostic or therapeutic plan. Level 5 describes patient outcome efficacy, being the percentage of patients who improve after the test compared with those without it, morbidities avoided, change in quality-adjusted life years (QALYs) based on the test, and similar metrics. Finally, level 6, societal efficacy, comprises the benefits and costs of the imaging strategy from a societal viewpoint. (18) (Table 1)

The value of cardiac imaging can be assessed if information about the higher levels of efficacy cited in the model is available. For a given condition, an imaging study can lead to changes in diagnostic thinking, such as uncovering the presence and severity of a disorder. Conversely, a test may confirm the absence of a condition, such a decline in left ventricular systolic function during a course of cancer chemotherapy, allowing treatment to continue as planned by the treating clinician. The test results bring about an evidence-based change in management that has been proven in randomized, controlled trials to improve patient outcomes. This approach might constitute an adequate surrogate for randomized, controlled trials of the imaging modality itself $(19,20)$

Aspects of the candidate imaging study itself also enter into the value equation. In all forms of testing, a good candidate predictor should have a favorable risk-benefit ratio, reasonable cost, acceptability and convenience, all of which are characteristic of echocardiography. (21) With respect to candidate conditions, a "commonsense checklist" would consist of the following. One should apply the predictor to diseases with major morbidity, for which some effective treatment is available which is not equally effective for all persons. The candidate test should allow more accurate classification of individuals into categories in which treatment is or is not indicated. The incremental prediction should be beyond what can be achieved with information which is already available. There should be consensus about and 
standardization of established predictors, and the predictor should be unambiguously defined and measured. (21)

\section{Opportunities to achieve high value cardiac imaging}

Examples of cardiac conditions with significant morbidity which fit these criteria abound. In each case, echocardiography reclassifies persons non-invasively, painlessly and without the use of ionizing radiation, based on standardized criteria such as those for chamber quantification, stress echocardiography and valvular regurgitation which have been promulgated in a series of guidelines published by ASE and ACCF. (22-24)

An example candidate condition is heart failure (HF), which affects an estimated 5.7 million people in the United States. (25) Many Class I recommended therapies for heart failure with reduced left ventricular ejection fraction are supported by Level of Evidence A; that is, they are recommended based on multiple randomized, controlled trials or meta-analyses conducted in multiple populations. Therapies including angiotensin converting enzyme inhibitors or angiotensin receptor blockers; beta blockers; implantable cardioverter-defibrillators for primary and secondary prevention of sudden cardiac death; and cardiac resynchronization have been shown to reduce symptoms, decrease hospitalizations and increase survival, depending on stage and symptom class. Treatment of systolic heart failure is predicated upon identifying the clinical predictor decreased systolic left ventricular function, usually via two-dimensional echocardiography, which is described as "[t]he single most useful diagnostic test in the evaluation of patients with HF." (26)

Chronic mitral regurgitation serves as another example. This disorder is characterized by a long latent period in which patients can remain asymptomatic even in the face of developing left ventricular dilation and systolic dysfunction; yet even patients with preserved left ventricular ejection fraction may be at increased risk of death. Mitral valve surgery performed in an asymptomatic individual whose 
ejection fraction has fallen below $60 \%$ is likely to prevent further deterioration in left ventricular function and improve longevity, although the level of evidence is less robust (Level B: limited populations evaluated; data derived from a single randomized trial or nonrandomized studies). Once the ejection fraction falls even lower, the risk of surgery increases and postoperative survival is less. Thus there exists a golden moment for patients with chronic severe mitral regurgitation, wherein identification of the severity of regurgitation and tracking left ventricular systolic function leads to surgical therapy which improves outcomes, and conversely where outcomes are appreciably worse if the golden moment is missed. (27)

Other conditions where opportunities exist to achieve high value cardiac imaging leading to effective, evidence-based treatments are listed in Table 2. (26, 28-31)

\section{Enhancing the likelihood that high value cardiac imaging is provided}

The risk of missed opportunities might increase as health care in the United States reorganizes into episodes of care for a specific patient, for a specified condition, over a defined period of time. Global payment schemes in which providers assume financial risk can be perceived as carrying with them financial incentives to underutilize services, including imaging. (32) It is thus incumbent on the cardiology profession to define what constitutes high value cardiac imaging in each care bundle or episode of care. Even under a fee-for-service system where there are no incentives to underutilize services, underuse of necessary care is common. (33) Nearly $40 \%$ of Medicare beneficiaries with newly diagnosed heart failure do not have an assessment of left ventricular function, a recommended performance measure for these patients. (34) Recent studies applying the appropriate use criteria to cardiac testing reveal evidence of missed opportunities to detect and correctly treat heart disease. A retrospective study of appropriate use criteria for coronary revascularization of patients with stable coronary artery disease revealed that only $69 \%$ of patients with an appropriate indication for 
revascularization actually underwent revascularization. (35) The 2011 appropriate use criteria for echocardiography were applied to 931 consecutive inpatients referred for transthoracic echocardiography in 5 community hospitals in Italy, who were compared with 259 patients who had been discharged without having been referred for an echocardiogram. The investigators determined that $14.7 \%$ of requested studies fell into the inappropriate category. However, among the patients discharged without an echocardiographic examination, $16.2 \%$ failed to have a study performed despite an appropriate indication, most commonly worsening signs or symptoms of heart failure. (10)

The universe of clinical conditions in which an echocardiogram may be indicated is large, and the task of deciding at what point the study becomes a high value test is challenging even for physicians trained in cardiology. Determining in the clinic or at the bedside when an echocardiogram meets "high value" criteria may be even more difficult for non-cardiologists, such as internal medicine specialist or general practice physicians, who order $71 \%$ of echocardiograms. (36) What tools are available to assist clinicians in ordering appropriate imaging tests for a given patient, while refraining from ordering ones of low value? Clinical decision support systems, defined as "any electronic system designed to aid directly in clinical decision making, in which characteristics of individual patients are used to generate patientspecific assessments or recommendations that are then presented to clinicians for consideration" are promising means by which to improve cardiac test ordering. (37) Four recent reviews found moderate strength evidence that decision support systems, integrated into computerized point of entry or electronic health record systems, can improve the appropriate ordering of clinical studies. Decision support systems varied in the effectiveness with which they improved the quality of care, as judged by health care process measures such as performing preventive services, diagnostic test ordering, and prescription of therapies. Data are sparse for effects on patient or economic outcomes. Few of the individual studies reviewed examined imaging. (38-41) 
From the foregoing, a two-sided paradigm for achieving high value cardiac imaging emerges, as cardiac imaging must be "right sized" in two directions. The issue of inappropriate overutilization has been recognized, and tools to identify and address it are appearing. Those initiatives work towards the important goal of reducing the number of imaging studies where the ratio of positive outcomes to dollars spent is unfavorable. In a complimentary manner, research is needed into scenarios where inappropriate underutilization takes place. Circumstances where a favorable ratio of health care value achieved relative to cost indicates that a study is high value must not be missed. A systematic approach for research into the latter would identify controlled trials of cardiac conditions where therapies which improve patient outcomes require imaging studies to detect candidates for treatment. Then, investigations would delineate methods which start with the patient at the point of care for his or her symptoms or condition, and alert care providers (some of whom may not be familiar with the nuances of appropriate cardiac testing) to order precisely the right test. An ideal system would provide real-time feedback so as to educate as well as inform the physician. Research would later be needed to discover whether beneficial changes take place in practice patterns, and more important in patient outcomes and societal efficacy.

Progress in this direction is evident from a recent prospective study which evaluated an appropriate use criteria decision support tool for physicians ordering imaging studies for coronary artery disease. The studies included stress echocardiography, as well as myocardial perfusion scintigraphy and coronary CT angiography. In addition to examining the effects on test appropriateness, the investigators studied the effects of using the tool on intended changes in medical therapy. The tool was employed at the point of ordering, took on average two minutes of physician time to use, and the immediate feedback to the physician provided an educational component. Comparing the first two months and the last two months of the trial, ordering of rarely appropriate studies decreased from $22 \%$ to $6 \%$, the percentage of 
appropriate studies increased from $49 \%$ to $61 \%$, and intended changes in medical therapy increased from $11 \%$ to $32 \% .(42)$

Multimodality, disease-specific appropriate use criteria for imaging are now beginning to appear with the publication of the 2013 document for cardiovascular imaging in heart failure. (43) This appropriate use document differs from prior publications not only because it is the first to encompass multiple imaging modalities. The authors identified five key clinical entry points or scenarios for heart failuredirected imaging, "emphasizing that each indication represents the specific 'point-of-order' for an imaging study." Each scenario reviews the rationale for imaging, delineates the choice of imaging modalities, references the heart failure guidelines, and categorizes the appropriateness of each modality. For the scenario "newly suspected or potential heart failure," appropriate use recommendations drill down to selection of imaging based on symptoms and signs, for malignancy with cardiotoxic therapy, familial or genetic cardiomyopathy, known adult congenital heart disease, and acute myocardial infarction.

\section{Envisioning a system for promoting high value cardiac testing}

One can hypothesize the form which an ideal system to ensure high value cardiac imaging might take. The process would use a decision support tool at the point of care or ordering. It would begin with a set of signs and symptoms or a disease state. Logic built into the decision support algorithm could automatically pull patient-specific descriptors which are already present in the database, such as the physical examination, severity of symptoms, co-morbid conditions such as malignancy, prior relevant imaging or laboratory values such as creatinine, for its impact on choosing a dye study, among others. By referencing appropriate use criteria for multimodality imaging, the system could prompt the clinician to consider ordering an appropriate study for each specific case where indicated. It might be designed to look back to prior, similar testing and, by matching elements in the report (such as mild, moderate or 
severe regurgitation) and patient descriptors (such as symptom severity), inform the clinician whether a study meets guideline recommendations to repeat the study, or whether to refrain from doing so if these criteria are not met.

A means to harmonize expert opinion from cardiology with guidelines for the same condition by experts in other disciplines might further improve test utilization. Conceptually, at least, clinicians might be most familiar with recommendations in their own specialty's literature. An example is syncope, a condition treated by emergency medicine specialists as well as cardiologists. Syncope is ranked in the echocardiography appropriate use guidelines as appropriate for "clinical symptoms or signs consistent with a cardiac diagnosis known to cause lightheadedness/presyncope/syncope." (44) Recommendations similar to these have been made in multidisciplinary guidelines for the investigation of syncope authored by experts in emergency medicine. $(45,46)$ Using decision rules found in the emergency medicine literature for patients presenting to emergency rooms with syncope may improve the diagnostic and therapeutic efficacy of echocardiography. Applying a syncope diagnostic protocol to patients presenting to a hospital in the United Kingdom increased the percentage of echocardiograms performed. Importantly, the authors noted that $75 \%$ of echocardiograms in the study group were performed for significant clinical findings such as aortic stenosis. Compared with historical controls, the number of examinations needed to make a diagnosis decreased significantly, implying that the percentage of low yield echocardiograms was reduced. (47)

Efforts to reduce low value imaging represent an important start in ensuring appropriate use of resources. Short term benefits are relatively easy to quantitate, at least economically in terms of dollars saved. We must at the same time recognize and address the thornier problem of missed opportunities for high value imaging. As the United States moves to value-based purchasing, diagnoses will be bundled into payment groups, and pressure will mount to reduce costs. Physicians must improve the way they 
order cardiac imaging, moving beyond cost to the concept of value. Inappropriate underutilization as well as overutilization must be reduced. In the latter case, failure to perform the right test at the right time can lead to an even more unfortunate circumstance for patients, described by hockey great Wayne Gretzky as "you miss $100 \%$ of the shots you never take."

\section{Acknowledgement}

The author thanks Michael S. Lauer, M.D. for his helpful suggestions. 


\section{References}

1. Emanuel EJ, Fuchs VR. The perfect storm of overutilization. JAMA. 2008 Jun 18;299(23):2789-91.

2. Palfrey S. Daring to practice low-cost medicine in a high-tech era. N Engl J Med. 2011 Mar 17;364(11):e21.

3. Medicare Payment Advisory Commission. Medicare Payment Advisory Commission. 2012 report to congress on Medicare payment policy. Washington, DC: Medicare Payment Advisory Commission; March 2012.

4. Levin DC, Rao VJ, Parker L, Frangos AJ. The sharp reduction in Medicare payments for noninvasive diagnostic imaging in recent years: Will they satisfy the federal policymakers? J Am Coll Radiol. 2012;9:643,-647.

5. Patel MR, Spertus JA, Brindis RG, Hendel RC, Douglas PS, Peterson ED, et al. ACCF proposed method for evaluating the appropriateness of cardiovascular imaging. J Am Coll Cardiol. 2005 Oct 18;46(8):160613.

6. Hendel RC, Patel MR, Allen JM, Min JK, Shaw LJ, Wolk MJ, et al. Appropriate use of cardiovascular technology: 2013 ACCF appropriate use criteria methodology update: A report of the American College of Cardiology Foundation Appropriate Use Criteria Task Force. J Am Coll Cardiol. 2013 Mar 26;61(12):1305-17.

7. Ward RP, Krauss D, Mansour IN, Lemieux N, Gera N, Lang RM, et al. Comparison of the clinical application of the American College of Cardiology Foundation/American Society of Echocardiography appropriateness criteria for outpatient transthoracic echocardiography in academic and community practice settings. Journal of the American Society of Echocardiography. 2009 Dec;22(12):1375-81.

8. Mansour IN, Lang RM, Aburuwaida WM, Bhave NM, Ward RP. Evaluation of the clinical application of the ACCF/ASE appropriateness criteria for stress echocardiography. Journal of the American Society of Echocardiography. 2010 Nov;23(11):1199-204.

9. Willens HJ, Hendel RC, Inhaber FR, Chakko SC, Postel C, Hasan T, et al. Appropriateness use criteria for transthoracic echocardiography: Relationship with radiology benefit managers preauthorization determination and comparison of the new (2010) criteria to the original (2007) criteria. Am Heart J. 2011 Oct;162(4):772-9.

10. Ballo P, Bandini F, Capecchi I, Chiodi L, Ferro G, Fortini A, et al. Application of 2011 American College of Cardiology Foundation/American Society of Wchocardiography appropriateness use criteria in hospitalized patients referred for transthoracic echocardiography in a community setting. Journal of the American Society of Echocardiography. 2012 Jun;25(6):589-98.

11. Bhave NM, Mansour IN, Veronesi F, Razi RR, Lang RM, Ward RP. Use of a web-based application of the American College of Cardiology Foundation/American Society of Echocardiography appropriateness 
use criteria for transthoracic echocardiography: A pilot study. Journal of the American Society of Echocardiography. 2011 Mar;24(3):271-6.

12. Aggarwal NR, Wuthiwaropas P, Karon BL, Miller FA, Pellikka PA, American College of Cardiology Foundation. Application of the appropriateness criteria for echocardiography in an academic medical center. Journal of the American Society of Echocardiography. 2010 Mar;23(3):267-74.

13. Allen JM. A national initiative to improve utilization of cardiac imaging: The FOCUS learning community and performance improvement module. Circulation: Cardiovascular Quality and Outcomes. 2011 November 2011;4(6 Supplement).

14. Imaging in "FOCUS." [Internet].: American College of Cardiology; 2013; cited April 19, 2013]. Available from: http://www.cardiosource.org/Science-And-Quality/Quality-Programs/Imaging-inFOCUS.aspx.

15. Douglas PS. Improving imaging: Our professional imperative. J Am Coll Cardiol. 2006 Nov 21;48(10):2152-5.

16. Porter ME. What is value in health care?. N Engl J Med. 2010 Dec 23;363(26):2477-81.

17. PROspective multicenter imaging study for evaluation of chest pain (PROMISE) [Internet].: U.S. National Institutes of Health; 2012 [updated August 2012; cited October 30, 2012]. Available from: http://clinicaltrials.gov/ct2/show/NCT01174550.

18. Fryback DG, Thornbury JR. The efficacy of diagnostic imaging. Medical Decision Making. 1991 AprJun;11(2):88-94.

19. Guyatt GH, Tugwell PX, Feeny DH, Haynes RB, Drummond M. A framework for clinical evaluation of diagnostic technologies. CMAJ Canadian Medical Association Journal. 1986 Mar 15;134(6):587-94.

20. Lord SJ, Irwig L, Simes RJ. When is measuring sensitivity and specificity sufficient to evaluate a diagnostic test, and when do we need randomized trials?. Ann Intern Med. 2006 Jun 6;144(11):850-5.

21. Ioannidis JP, Tzoulaki I. What makes a good predictor?: The evidence applied to coronary artery calcium score. JAMA. 2010 Apr 28;303(16):1646-7.

22. Lang RM, Bierig M, Devereux RB, Flachskampf FA, Foster E, Pellikka PA, et al. Recommendations for chamber quantification: A report from the American Society of Echocardiography's Guidelines and Standards Committee and the Chamber Quantification Writing Group, developed in conjunction with the European Association of Echocardiography, a branch of the European Society of Cardiology. Journal of the American Society of Echocardiography. 2005 Dec;18(12):1440-63.

23. Pellikka PA, Nagueh SF, Elhendy AA, KuehI CA, Sawada SG, American Society of Echocardiography. American Society of Echocardiography recommendations for performance, interpretation, and application of stress echocardiography. Journal of the American Society of Echocardiography. 2007 Sep;20(9):1021-41. 
24. Zoghbi WA, Enriquez-Sarano M, Foster E, Grayburn PA, Kraft CD, Levine RA, et al. Recommendations for evaluation of the severity of native valvular regurgitation with two-dimensional and Doppler echocardiography. Journal of the American Society of Echocardiography. 2003 Jul;16(7):777-802.

25. Roger VL, Go AS, Lloyd-Jones DM, Benjamin EJ, Berry JD, Borden WB, et al. Heart disease and stroke statistics--2012 update: A report from the American Heart Association. Circulation. 2012 Jan 3;125(1):e2-e220.

26. Hunt SA, Abraham WT, Chin MH, Feldman AM, Francis GS, Ganiats TG, et al. 2009 focused update incorporated into the ACC/AHA 2005 guidelines for the diagnosis and management of heart failure in adults A report of the American College of Cardiology Foundation/American Heart Association Task Force on Practice Guidelines developed in collaboration with the International Society for Heart and Lung Transplantation. J Am Coll Cardiol. 2009 Apr 14;53(15):e1-e90.

27. Bonow RO. Carabello BA. Chatterjee K. de Leon AC Jr. Faxon DP. Freed MD. Gaasch WH. Lytle BW. Nishimura RA. O'Gara PT. O'Rourke RA. Otto CM. Shah PM. Shanewise JS. American College of Cardiology/American Heart Association Task Force on Practice Guidelines. 2008 focused update incorporated into the ACC/AHA 2006 guidelines for the management of patients with valvular heart disease: A report of the American College of Cardiology/American Heart Association Task Force on Practice Guidelines (Writing Committee to Revise the 1998 Guidelines for the Management of Patients with Valvular Heart Disease). endorsed by the Society of Cardiovascular Anesthesiologists, Society for Cardiovascular Angiography and Interventions, and Society of Thoracic Surgeons. J Am Coll Cardiol. 2008 Sep 23;52(13):e1-142.

28. American College of Emergency Physician, Society for Cardiovascular Angiography and Interventions, O'Gara PT, Kushner FG, Ascheim DD, Casey DE,Jr, et al. 2013 ACCF/AHA guideline for the management of ST-elevation myocardial infarction: A report of the American College of Cardiology Foundation/American Heart Association Task Force on Practice Guidelines. J Am Coll Cardiol. 2013 Jan 29;61(4):e78-140.

29. Epstein AE, DiMarco JP, Ellenbogen KA, Estes NA,3rd, Freedman RA, Gettes LS, et al. 2012 ACCF/AHA/HRS focused update incorporated into the ACCF/AHA/HRS 2008 guidelines for device-based therapy of cardiac rhythm abnormalities: A report of the American College of Cardiology Foundation/American Heart Association Task Force on Practice Guidelines and the Heart Rhythm Society. J Am Coll Cardiol. 2013 Jan 22;61(3):e6-75.

30. Gersh BJ, Maron BJ, Bonow RO, Dearani JA, Fifer MA, Link MS, et al. 2011 ACCF/AHA guideline for the diagnosis and treatment of hypertrophic cardiomyopathy: Executive summary: A report of the American College of Cardiology Foundation/American Heart Association Task Force on Practice Guidelines. J Am Coll Cardiol. 2011 Dec 13;58(25):2703-38.

31. Baddour LM. Wilson WR. Bayer AS. Fowler VG Jr. Bolger AF. Levison ME. Ferrieri P. Gerber MA. Tani LY. Gewitz MH. Tong DC. Steckelberg JM. Baltimore RS. Shulman ST. Burns JC. Falace DA. Newburger JW. Pallasch TJ. Takahashi M. Taubert KA. Committee on Rheumatic Fever, Endocarditis, and Kawasaki Disease. Council on Cardiovascular Disease in the Young. Councils on Clinical Cardiology, Stroke, and Cardiovascular Surgery and Anesthesia. American Heart Association. Infectious Diseases Society of America. Infective endocarditis: Diagnosis, antimicrobial therapy, and management of complications: A statement for healthcare professionals from the Committee on Rheumatic Fever, Endocarditis, and 
Kawasaki disease, Council on Cardiovascular Disease in the Young, and the Councils on Clinical Cardiology, Stroke, and Cardiovascular Surgery and Anesthesia, American Heart Association: Endorsed by the Infectious Diseases Society of America. Circulation. 2005 Jun 14;111(23):e394-434.

32. Mechanic RE, Altman SH. Payment reform options: Episode payment is a good place to start. Health Aff. 2009 Mar-Apr;28(2):w262-71.

33. Asch SM, Sloss EM, Hogan C, Brook RH, Kravitz RL. Measuring underuse of necessary care among elderly Medicare beneficiaries using inpatient and outpatient claims. JAMA. 2000 Nov 8;284(18):232533.

34. Curtis LH, Greiner MA, Shea AM, Whellan DJ, Hammill BG, Schulman KA, et al. Assessment of left ventricular function in older medicare beneficiaries with newly diagnosed heart failure. Circulation.Cardiovascular Quality \& Outcomes. 2011;4(1):85-91.

35. Ko DT, Guo H, Wijeysundera HC, Natarajan MK, Nagpal AD, Feindel CM, et al. Assessing the association of appropriateness of coronary revascularization and clinical outcomes for patients with stable coronary artery disease. J Am Coll Cardiol. 2012 Nov 6;60(19):1876-84.

36. Pearlman AS, Ryan T, Picard MH, Douglas PS. Evolving trends in the use of echocardiography: A study of Medicare beneficiaries. J Am Coll Cardiol. 2007 Jun 12;49(23):2283-91.

37. Kawamoto K, Houlihan CA, Balas EA, Lobach DF. Improving clinical practice using clinical decision support systems: A systematic review of trials to identify features critical to success. BMJ. $2005 \mathrm{Apr}$ 2;330(7494):765.

38. Garg AX, Adhikari NK, McDonald H, Rosas-Arellano MP, Devereaux PJ, Beyene J, et al. Effects of computerized clinical decision support systems on practitioner performance and patient outcomes: $A$ systematic review. JAMA. 2005 Mar 9;293(10):1223-38.

39. Roshanov PS, You JJ, Dhaliwal J, Koff D, Mackay JA, Weise-Kelly L, et al. Can computerized clinical decision support systems improve practitioners' diagnostic test ordering behavior? A decision-makerresearcher partnership systematic review. Implementation Science. 2011;6:88.

40. Jaspers MW, Smeulers M, Vermeulen H, Peute LW. Effects of clinical decision-support systems on practitioner performance and patient outcomes: A synthesis of high-quality systematic review findings. Journal of the American Medical Informatics Association. 2011 May 1;18(3):327-34.

41. Bright TJ, Wong A, Dhurjati R, Bristow E, Bastian L, Coeytaux RR, et al. Effect of clinical decisionsupport systems: A systematic review. Ann Intern Med. 2012 Jul 3;157(1):29-43.

42. Lin FY, Dunning AM, Narula J, Shaw LJ, Gransar H, Berman DS, et al. Impact of an automated multimodality point-of-order decision support tool on rates of appropriate testing and clinical decision making for individuals with suspected coronary artery disease: A prospective multicenter study. J Am Coll Cardiol 2013 Jul 23;62:308-16. 
43. Patel MR, White RD, Abbara S, Bluemke DA, Herfkens RJ, Picard M, et al. 2013 ACCF/ACR/ASE/ASNC/SCCT/SCMR appropriate utilization of cardiovascular imaging in heart failure. A joint report of the American College of Radiology Appropriateness Criteria Committee and the American College of Cardiology Foundation Appropriate Use Criteria Task Force. Journal of the American College of Cardiology. 2013 May 28;61(21):2207-31.

44. American College of Cardiology Foundation Appropriate Use Criteria Task,Force, American Society of Echocardiography, American Heart Association, American Society of Nuclear Cardiology, Heart Failure Society of America, Heart Rhythm Society, et al. ACCF/ASE/AHA/ASNC/HFSA/HRS/SCAI/SCCM/SCCT/SCMR 2011 appropriate use criteria for echocardiography. A report of the American College of Cardiology Foundation Appropriate Use Criteria Task Force, American Society of Echocardiography, American Heart Association, American Society of Nuclear Cardiology, Heart Failure Society of America, Heart Rhythm Society, Society for Cardiovascular Angiography and Interventions, Society of Critical Care Medicine, Society of Cardiovascular Computed Tomography, Society for Cardiovascular Magnetic Resonance, American College of Chest Physicians. Journal of the American Society of Echocardiography. 2011 Mar;24(3):229-67.

45. Sheldon RS, Morillo CA, Krahn AD, O'Neill B, Thiruganasambandamoorthy V, Parkash R, et al. Standardized approaches to the investigation of syncope: Canadian Cardiovascular Society position paper. Can J Cardiol. 2011 Mar-Apr;27(2):246-53.

46. Task Force for the Diagnosis and Management of Syncope. European Society of Cardiology (ESC). European Heart Rhythm Association (EHRA). Heart Failure Association (HFA). Heart Rhythm Society (HRS). Moya A. Sutton R. Ammirati F. Blanc JJ. Brignole M. Dahm JB. Deharo JC. Gajek J. Gjesdal K. Krahn A. Massin M. Pepi M. Pezawas T. Ruiz Granell R. Sarasin F. Ungar A. van Dijk JG. Walma EP. Wieling W. Guidelines for the diagnosis and management of syncope (version 2009). Eur Heart J. 2009 Nov;30(21):2631-71.

47. Farwell DJ, Sulke AN. Does the use of a syncope diagnostic protocol improve the investigation and management of syncope?. Heart. 2004 Jan;90(1):52-8. 
Figure Legends

Figure 1. Dimensions of care framework for evaluating quality of cardiovascular imaging.

From Douglas, P.; Chen, J.; Gillam, L.; Hendel, R.; Jollis, J.; Iskandrian, A.E.; Krumholz, H.M.; Massoudi, F.; Mohler, E. III; McNamara, R.L.; Patel, M.R.; Peterson, E.; Spertus, J. Achieving quality in cardiovascular imaging: proceedings from the American College of Cardiology-Duke University Medical Center Think Tank on Quality in Cardiovascular Imaging. J Am Coll Cardiol 2006;48:2141-2151. Reproduced with permission of Elsevier, Inc. 